\title{
Editorial
}

\section{Cer'ebrovascular Diseases}

\section{The Challenge of Interdisciplinary Stroke Cooperation: Time for a Change!}

The Editor-in-Chief, Managing Editor, Associate Editors, and Editorial Board members wish to express their appreciation to all ad hoc reviewers of Cerebrovascular Diseases and Cerebrovascular Diseases Extra for their critical evaluation and competent comments on the manuscripts submitted to both journals. Rather than listing their individual names, as we did in the past, we once again take the opportunity to thank them all for their commitment and expertise - in particular, those who supported the journal by submitting excellent articles and reviews during the last year.

We were challenged by the introduction of a new submission and evaluation system provided by our publisher in 2017, which will hopefully support and facilitate the review process in the future. We will be glad to receive your valuable feedback and suggestions as to how it actually will improve the journal's timely and best possible management based on your experiences.

Many thanks are also due to those who have participated in the review processes and the management of our sister journal Cerebrovascular Diseases Extra. This journal has started to gain increasing prominence due to the rise in the number of meaningful and relevant contributions in terms of innovative pilot studies, hypothesis-generating reports and specially selected short communications. Because of such successful work, this journal has found its place in the recent listing of the Emerging Sourc- es Citation Index, published in the Web of Science with an own Impact Factor of 1.43.

Cerebrovascular Diseases is considered one of the world's highest ranked top Stroke Journals, thanks to the enormous work of all authors, editorial board members, and ad hoc reviewers in Europe, Asia, and North America as well as other parts of the world. The journal acknowledges the continuous support received from the highest referenced European Stroke Conference faculty and participants. This journal is growing in its reputation because of timely and relevant presentations and referential publications in the best scientific work in Europe and beyond (Asia and North America/Canada in particular). This has been possible due to the excellent cooperation extended by the European Stroke Research Foundation esrf, which is the new official partner of the journal, and due to the affiliation with both the ASIA Pacific Stroke Organisation and the International Stroke Summit. Another major reason for this achievement is the outstanding and highly appreciated contributions by Peter Roth, the director of Karger Publishers, Basel.

Highlights of original papers and special editorial introductions have been published in selected issues in 2017, and this initiative will continue even this year. These articles will be presented for free access in addition to already being available for open reviews so that a better and more comprehensive overview can be obtained about the 
journals full contents. We start 2018 by publishing 2 original papers, which illustrate the increasing number of multidisciplinary stroke research studies supported by different medical specialties in addition to neurology and neurosurgery or neuroradiology. This interdisciplinary research cooperation is also a highlight in the program of the 27th European Stroke Conference in Athens, to be held on April 11-13, 2018

1 . The first paper is from a systematic literature research examining the prevalence and mortality risk of stroke patients with acute kidney injury (AKI) as a complication submitted by A. Zorrilla-Vaca et al. [1] from the United States. This meta-analysis provides evidence that $\mathrm{AKI}$ is a common complication following both acute ischemic stroke (AIS) and intracerebral hemorrhage and is associated with increased mortality following AIS but not intracerebral hemorrhage. This highlights the need for early assessment of renal function in the acute phase of AIS, in particular, and avoidance of factors that may induce AKI in vulnerable patients; 1b. Along with our Review on primary prevention of stroke in chronic kidney disease patients, a scientific update submitted by Bilha et al. [2] from Romania has also been included;

2. The second is a paper from a work submitted by Selvik et al. [3] from Norway challenging the need to ascertain which first stroke patients should be considered for detailed cancer-diagnostic investigations as the first manifestation of so far unknown cancer. Active cancer was found in 5\% of our ischemic stroke patients and a clinical score comprising elevated D-dimer $\geq 3 \mathrm{mg} / \mathrm{L}$, lower $\mathrm{Hb} \leq 12.0 \mathrm{~g} / \mathrm{dL}$, and a history of previous or current smoking.

The following original paper has also been included for free access:

Computed tomography perfusion-derived bloodbrain barrier permeability does not yet improve the prediction of hemorrhagic transformation [4].

M.G. Hennerici, Mannheim

\section{References}

1 Zorrilla-Vaca A, Ziai W, Connolly ES Jr, Geocadin R, Thompson R, Rivera-Lara L: Acute kidney injury following acute ischemic stroke and intracerebral hemorrhage: a meta-analysis of prevalence rate and mortality risk. Cerebrovasc Dis 2018;45:1-9.
2 Bilha SC, Burlacu A, Siriopol D, Voroneanu L, Covic A: Primary prevention of stroke in chronic kidney disease patients: a scientific update. Cerebrovasc Dis 2018;45:33-41.

3 Selvik HA, Bjerkreim AT, Thomassen L, Waje-Andreassen U, Naess H, Kvistad CE: When to screen ischaemic stroke patients for cancer. Cerebrovasc Dis 2018;45: 42-47.
4 Horsch AD, Bennink E, van Seeters T, Kappelle LJ, van der Graaf Y, Mali WPTM, de Jong HWAM, Velthuis BK, Dankbaar JW; DUST Investigators: Computed tomography perfusion derived blood-brain barrier permeability does not yet improve prediction of hemorrhagic transformation. Cerebrovasc Dis 2018;45:26-32. 